\title{
METODE VALUASI MANAKAH YANG LEBIH TEPAT UNTUK MERGER DAN AKUISISI?
}

\author{
Suwinto Johan ${ }^{1}$, Laura Herbani ${ }^{2}$ \\ ${ }^{1}$ STIE Wiyatamandala, Jakarta \\ Email: suwintojohan@gmail.com \\ ${ }^{2}$ Program Studi Magister Manajemen, Universitas Tarumanagara \\ Email: herbani_laura@yahoo.com
}

\begin{abstract}
The aim of this research is to study the various valuation methods in merger and acquisition transaction. Valuation is the most important part of a merger and acquisition deal. The seller always expects the highest value, however the buyer will expect to have a reasonable value of the target. It is important both parties agree and understand the basic views. The research will be focused on the most important variables and the valuation process of each method. The research will provide advantages and disadvantages of each method. The research also stated 3 important points in valuation, which are scarcity, regulation and time of valuation.
\end{abstract}

Kata Kunci : Akuisisi, Merger, Nilai Perusahaan, Valuasi

JEL Clarification Code : G32, G33, G34

\section{PENDAHULUAN}

Dalam setiap transaksi merger dan akusisi memiliki beberapa tahapan yang dilakukan. Tahapan awal dimulai dari persiapan informasi awal, dilanjutkan kesepakatan awal nilai valuasi akuisisi dengan nilai kisaran tertentu antara perusahaan pengakuisisi dengan perusahaan target. Selanjutnya, dilakukan due diligence untuk menelaah kondisi perusahaan sesuai dengan informasi yang diperoleh.

Setelah transaksi, maka integrasi menjadi faktor yang penting. Li and Jiang (2014) memberikan beberapa usulan kepada perusahaan China dalam merger dan akuisisi, yakni mengembangkan strategi rasional untuk merger dan akuisisi, mengembangkan jalur pembiayaan dan diversifikasi pembiayaan, memperhatikan faktor integrasi sesudah merger dan akuisisi.

Setelah due diligence, dilanjutkan dengan melakukan valuasi kembali terhadap perusahaan target atas data-data yang diperoleh selama due diligence. Nilai valuasi di tahap ini akan menjadi bahan negosiasi untuk mencapai kesekapatan antara pembeli dan penjual (Johan, 2017).

Secara umum, kedua belah pihak dalam M\&A memiliki pandangan yang berbeda mengenai valuasi. Penjual cenderung untuk memberikan valuasi lebih tinggi dan pembeli akan memberikan nilai valuasi yang lebih rendah terhadap target perusahaan (Tikhile, 2014).

Dalam transaksi merger dan akuisisi, valuasi merupakan sebuah tahapan yang penting. Pada tahapan ini dilakukan penilaian terhadap perusahaan target yang akan diakuisisi oleh perusahaan pengakuisisi. Tahapan ini juga merupakan tahapan dimana pembeli dan penjual menyamakan persepsi mengenai perusahaan target yang akan diakuisisi. 
Pospisil (2015) mengemukakan bahwa selain pendapatan, margin keuntungan, dan suku bunga diskonto, hal lain yang paling krusial adalah tanggal valuasi. Tanggal valuasi ini menentukan nilai proyeksi dan berhubungan dengan nilai valuasi. Kesepakatan antara para pihak menjadi penting tentang tanggal valuasi.

Dalam valuasi, kita menemukan beberapa pertanyaan:

a. Bagaimana kita melakukan valuasi?

b. Bagaimana menemukan metode valuasi yang terbaik?

Hal-hal ini yang selalu menjadi pertanyaan oleh perusahaan pembeli dan juga penjual terhadap perusahaan target. Hal-hal tersebut akan dibahas pada bagian berikut ini.

\section{PEMBAHASAN}

\section{Metode Nilai Buku (Book Value)}

Metode Nilai Buku dipergunakan secara umum dengan melihat nilai buku perusahaan yang tercamtum pada laporan keuangan perusahaan. Nilai buku yang menjadi ukuran adalah nilai total ekuitas atau total nilai aset dikurangi nilai total kewajiban pada perusahaan. Nilai ekuitas, nilai aset, dan nilai kewajiban merupakan nilai yang tercantum pada neraca.

Nilai buku merupakan cerminan nilai perusahaan pada saat laporan keuangan itu dibuat. Nilai buku merupakan akumulasi kinerja historical sejak perusahaan berdiri hingga laporan keuangan dibuat.

Nazir dan Malhotra (2017) menemukan bahwa kepemilikan memiliki implikasi pada valuasi nilai buku dan nilai pasar perusahaan. Penelitian didasarkan pada Bombay Stock Exchange (BSE) 100 perusahaan dengan menggunakan metode valuasi nilai buku dan nilai pasar.

Nilai buku ini dipengaruhi oleh beberapa faktor di antaranya adalah:

1. Metode pencatatan aktiva tetap dimana menyangkut metode penyusutan yang dilakukan;

2. Metode pencatatan persediaan barang baik bahan baku, bahan dalam proses dan juga barang jadi;

3. Metode penyesuaian terhadap kewajiban mata uang asing termasuk transaksi hedging;

4. Metode pencatatan lainnya seperti transaksi yang di luar neraca (off balance sheet) seperti penjaminan, kewajiban hukum yang masih dalam proses.

\section{Metode Nilai Pasar (Market Value)}

Metode Nilai Pasar merupakan metode nilai pasar dari harga saham yang beredar. Metode ini merupakan hasil dari penawaran dan permintaan antara investor pada bursa saham.

Pada umumnya, nilai saham yang dipergunakan adalah nilai rata-rata daripada harga saham selama beberapa waktu ke belakang. Nilai rata-rata harga saham pada umumnya, berkisar antara 90 hari hingga 360 hari. Tujuannya adalah agar nilai rata-rata ini lebih mencerminkan kondisi sebenarnya dan tidak menimbulkan abnormalitas.

Nilai pasar merupakan kumpulan transaksi yang terjadi di bursa. Nilai ini bisa merupakan transaksi yang aktif dan juga yang minimum misalnya hanya 1 lot. Sehingga jika nilai pasar dipergunakan sebagai patokan, maka nilai transaksi yang terjadi perlu menjadi bahan pertimbangan. Andriosopoulos et al. (2015) menemukan bahwa investor jangka panjang meningkatkan nilai pasar 
jangka panjang. Penelitian ini juga menemukan bahwa institusi domestik memitigasi kinerja jangka pendek yang kurang baik.

Untuk perusahaan tertutup, nilai pasar dari saham tidak dapat diperoleh. Pada umumnya, untuk nilai pasar perusahaan perusahaan tertutup akan merujuk kepada perusahaan terbuka yang sejenis sebagai referensi harga.

Ada kalanya, nilai pasar valuasi juga merujuk kepada nilai rata-rata dari para analis pasar modal yang menfokuskan pada perusahaan tertentu. Nilai ini merupakan nilai kesepakatan para analis.

\section{Metode Nilai Likuidasi (Liquidation Value)}

Metode Nilai Liquidasi merupakan metode yang didasarkan pada nilai perusahaan jika perusahaan tersebut dilikuidasi. Pada umumnya, metode ini dipergunakan jika perusahaan telah diputuskan akan pailit atau dalam proses negosiasi Penundaaan Kewajiban Pembayaran Utang (PKPU).

Tahapan dalam metode ini adalah:

1. Menilai aset yang memiliki nilai atau harga;

2. Mengidentifikasi kewajiban yang perlu dibayar termasuk kewajiban kepada negara dan juga karyawan;

3. Melakukan pemanggilan para kreditur baik yang memiliki jaminan maupun tanpa jaminan untuk melakukan verifikasi jumlah kewajiban;

4. Melakukan proses penjualan/pelelangan terhadap aset yang ada;

5. Melunasi kewajiban kreditur berdasarkan jaminan dengan hasil penjualan aset;

6. Jika terdapat kelebihan akan dikembalikan kepada pemegang saham, jika tidak maka akan dialokasikan sepenuhnya pada pihak-pihak yang memiliki kewajiban.

Salah satu contoh kasus pailit adalah PT. Metro Batavia (Batavia Air). Pada kasus ini total utang Rp. 2,54 Trilliun, sedangkan total lelang aset hanya Rp.40 Milliar. Sehingga, secara total mengalami negative sebesar Rp. 2,5 Trilliun.

\section{Metode Sum of The Part}

Metode ini menjumlahkan nilai-nilai anak perusahaan atau divisi yang dimiliki perusahaan. Adapun tahapan dalam metode ini adalah:

1. Menjumlahkan nilai-nilai anak perusahaan, jika perusahaan merupakan perusahaan induk. Jika perusahaan memiliki beberapa divisi, maka nilai masing-masing divisi akan dijumlahkan;

2. Dikurangi dengan biaya-biaya yang dikeluarkan atas transaksi merger dan akuisisi ini;

3. Ditambahkan dengan nilai sinergi yang dihasilkan sebagai hasil merger dan akuisisi;

4. Dikurangi dengan nilai unit bisnis atau anak perusahaan yang tidak diperbolehkan digabungkan oleh regulator sejalan dengan peraturan persaingan usaha. 


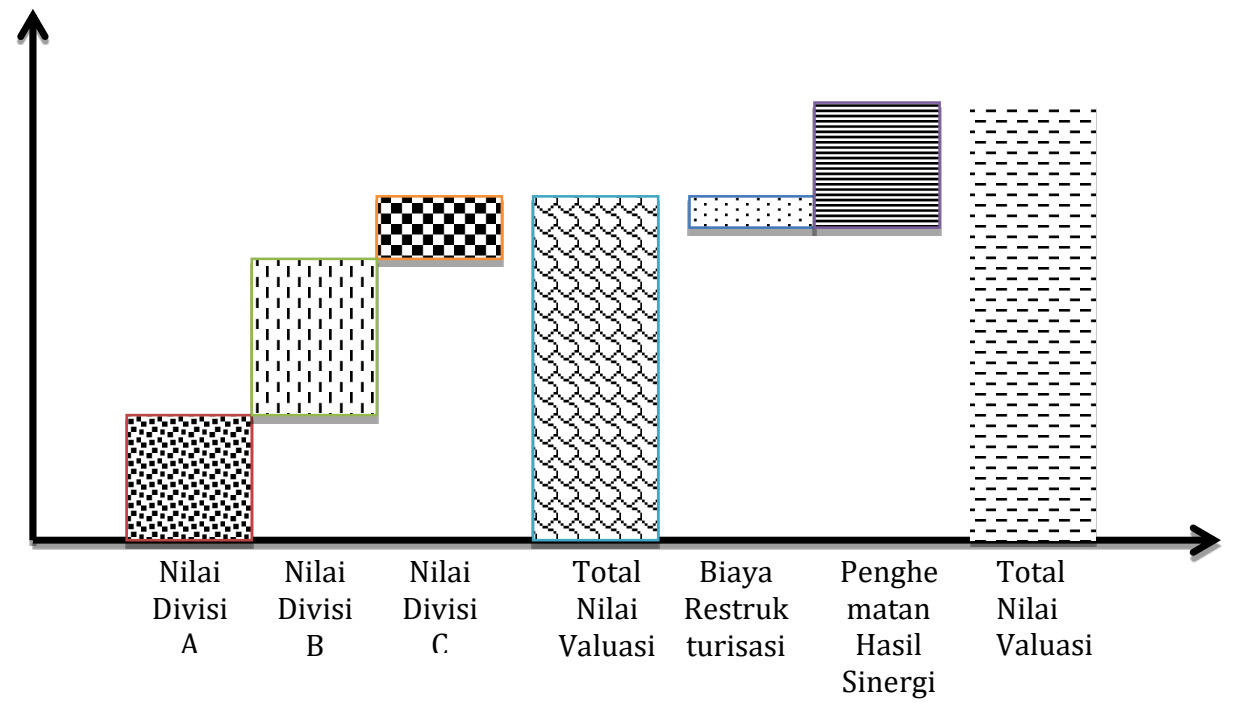

Gambar 1 Metode Sum of The Part

Metode ini valuasi ini dipergunakan oleh $\mathrm{P} \& \mathrm{G}$ ketika melakukan akuisisi terhadap Gillette. Masing-masing divisi Gillette divaluasi, kemudian dijumlahkan dan dikurangi dengan penghematan. Metode ini dipergunakan, jika ada bagian atau divisi yang harus dikeluarkan dari transaksi. Divisi atau bagian ini dilarang oleh regulator untuk digabungkan karena potensi monopoli.

\section{Metode Diskonto Arus Kas (Discounted Cash Flow)}

Metode ini berfokus pada masa depan perusahaan. Metode ini membuat proyeksi keuangan untuk jangka waktu panjang sebagai hasil sinergi antara 2 perusahaan yang mengalami merger dan akuisisi.

Konsep dari pendekatan ini adalah didasarkan pada suatu "premises", bahwa seseorang (investor) membeli (memiliki) suatu aset bukan karena sekedar ingin memiliki, tetapi mengharapkan hasil/return yang akan dihasilkan aset tersebut di masa mendatang (Ruslim, 2008).

Metode ini memasukkan nilai tambah atau sinergi yang akan dihasilkan akibat merger dan akuisisi. Nilai tambahan ini bisa berbentuk economies of scope dan economies of scale. (Baye, 2010). Salah satu contoh adalah Bank of Tokyo-Mitsubishi UFJ LTD (BTMU) akan membeli sebanyak 1,926 juta saham dari Asia Financial (Indonesia) Pte Ltd (AFI) dan afiliasinya sekitar 20,1\% dari total saham yang ditempatkan. Dengan rencana aksi korporasi ini, maka susunan pemegang saham PT Bank Danamon Tbk yang diusulkan adalah BMTU akan menjadi pemegang 3,833 miliar saham dengan total nilai Rp1,916 triliun, yang mewakili 40\%. Nilai akuisisi ini diperkirakan mempergunakan proyeksi keuangan ke depan.

Tahapan dalam Metode Discounted Cash Flow adalah:

1. Membuat proyeksi keuangan jangka panjang dengan memasukkan proyeksi sinergi daripada penggabungan 2 perusahaan;

2. Menghitung nilai arus kas yang akan diperoleh pada masing-masing tahun proyeksi;

3. Melakukan present value terhadap nilai arus kas pada masing-masing tahun dengan tingkat suku bunga;

4. Menjumlahkan nilai arus kas hasil present value yang diperoleh; 
5. Mengurangi nilai awal investasi atau nilai valuasi akuisisi yang akan dikeluarkan;

6. Jika diperoleh nilai positif, maka investasi dianggap masih layak.

Ada beberapa hal yang menjadi perhatian pada metode ini adalah:

1. Suku bunga yang dipergunakan sebagai landasan untuk present value. Menurut Ruslim (2008), suku bunga didiskontokan ke nilai sekarang dengan menggunakan cost of capital perusahaan. Asumsi cost of capital yang dipergunakan berdasarkan dari capital structure yang ada yaitu cost of debt dan cost of equity;

2. Cara membuat proyeksi termasuk kenaikan pendapatan dan biaya dihubungkan dengan tingkat inflasi, suku bunga kurs, dan juga siklus ekonomi;

3. Nilai arus kas yang diperoleh dihubungkan dengan metode penyusutan yang dipergunakan.

\section{Metode Relative Market Value}

Metode ini memperhitungkan nilai valuasi didasarkan pada transaksi yang terjadi pada perusahaan sejenis yang ada di industri yang sama. Perhitungan metode ini didasarkan pada nilai relatif antara perusahaan target dan perusahaan sejenis yang ada di pasar.

Declerck (2016) menjelaskan bahwa transaksi berdasarkan market multiples telah dipakai secara luas dalam negosiasi antara penjual dan pembeli. Penelitian ini fokus pada kinerja keuangan berdasarkan market multiples dari penjualan, EBITDA dan laba bersih dari tahun 2002-2009. Salah satu yang banyak memakai relative market value adalah perusahaan-perusahaan start-up. Valuasi Go-Jek sebesar lebih dari Rp. 56 Trilliun, didasarkan pada relative market value.

Metode ini perlu melakukan penyesuaian beberapa hal:

1. Mengumpulkan data-data perusahaan yang telah memiliki valuasi atau transaksi merger dan akuisisi;

2. Memilih perusahaan yang sejenis dengan perusahaan target dari segi ukuran, jenis usaha, lokasi geografis dan kesamaan lainnya;

3. Membandingkan antara perusahaan target dengan valuasi perusahaan sejenis.

Metode ini memiliki beberapa kekurangan:

1. Perusahaan sejenis yang persis sama tidak mudah diperoleh sebagai pembanding;

2. Perusahaan yang unik dengan pasar monopolistik atau monopoli akan mengalami kesulitan dalam mencari data nilai relatif. Perusahaan listrik, perusahaan telekomunikasi, perusahaan gas maupun perusahaan air yang dikuasai oleh negara, akan tidak mudah dalam mencari perusahaan pembanding.

Selain metode-metode di atas, metode valuasi untuk perusahaan yang baru berkembang memiliki metode valuasi yang berbeda. Valuasi perusahaan start-up (baru berkembang) di bidang teknologi memasukkan beberapa faktor lainnya, seperti potensi berkembang, risiko yang terkandung, potensi pengembalian investor, dan lainnya (Nazzer, 2017). 


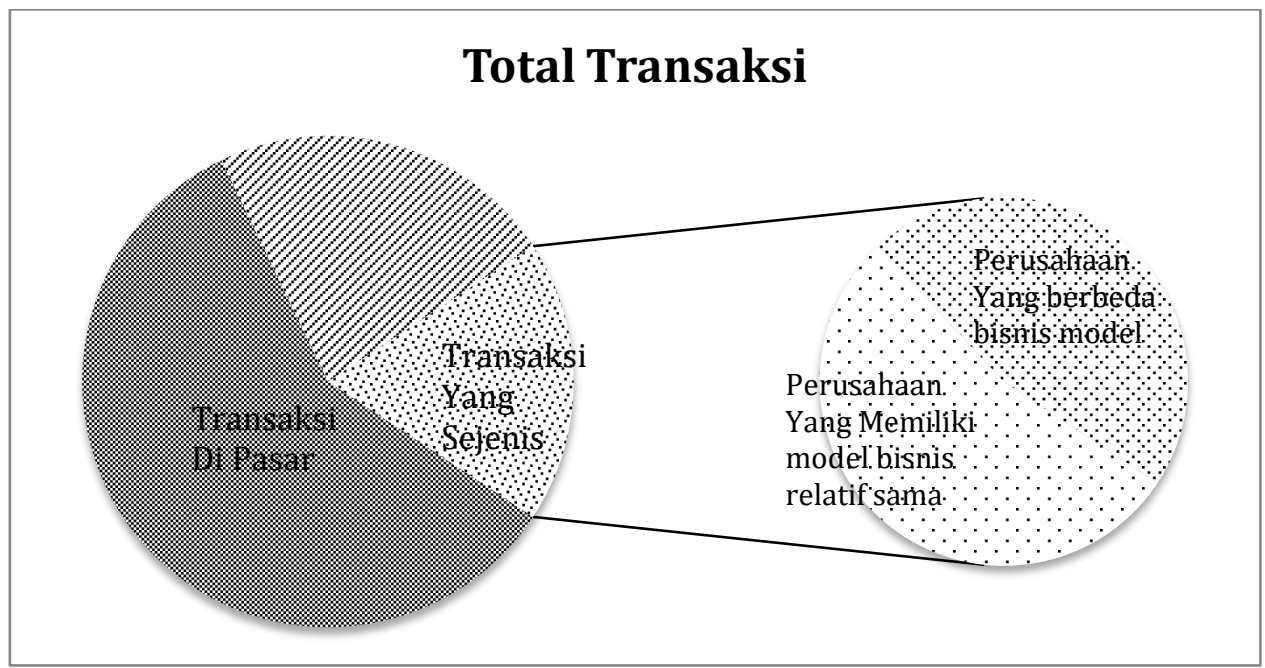

Gambar 2 Transaksi Sejenis Dalam Merger dan Akuisisi

\section{Faktor-Faktor yang Penting dalam Valuasi}

\section{a. Scarcity}

Ada beberapa industri yang sangat kompetitif, sehingga perusahaan yang ingin dijual, menjadi sedikit. Industri ini sangat menarik, sehingga tidak ada yang mau didivestasikan, sedangkan investor yang ingin investasi banyak. Sehingga kita perlu memperhatikan hal ini. Hal ini kita sebut dengan istilah scarcity (Johan, 2017).

Walaupun nilai valuasi tidak bisa mencapai harga tinggi, tetapi karena kekuatan antara permintaan dan penawaran, nilai valuasi menjadi tinggi. Transaksi relatif juga tidak diperoleh di pasar.

\section{b. Regulasi}

Regulator memegang peranan penting dalam transaksi merger dan akuisisi. Regulator akan memberikan ijin atas transaksi yang dilakukan. Regulator di Indonesia dikenal dengan Komisi Pemantau Persaingan Usaha (KPPU).

Jika ijin sebuah industri telah dikeluarkan, maka industri akan menjadi menarik bagi para pelaku usaha. Sebaliknya, jika regulator telah menaikkan persyaratan minimum seperti modal minimum, maka pelaku usaha akan terpaksa melakukan merger usahanya agar bisa memenuhi persyaratan yang ada.

\section{c. Waktu Valuasi}

Waktu dilakukan valuasi menjadi krusial karena menjadi landasan dalam menentukan nilai dan asumsi-asumsi. Penentuan tanggal perlu menjadi kesepakatan para pihak. Akan tetapi, Bertsatos et al. (2017) mengemukakan bahwa nilai valuasi industri perbankan tidak memiliki perbedaan antara sebelum dan sesudah krisis terjadi.

\section{KESIMPULAN}

Dari metode-metode di atas, kita dapat mengetahui tujuan dari masing-masing valuasi yang ada. Sehingga metode yang dipergunakan tergantung pada kondisi yang kita hadapi. Ada beberapa pendekatan yang berbeda, sehingga kita tidak mungkin hanya mempergunakan satu metode dalam valuasi. Metode terbaik dalam valuas adalah metode dengan nilai valuasi yang diterima oleh penjual dan pembeli. 
Tabel 1. Perbandingan Metode Metode Valuasi

\begin{tabular}{llll}
\hline & Sumber Data & Jenis Data & Keterangan \\
\hline 1. Book Value & Internal & Sekarang & $\begin{array}{l}\text { Akumulasi kinerja sejak } \\
\text { berdiri }\end{array}$ \\
\hline 2. Market Value & Eksternal & Sekarang & $\begin{array}{l}\text { Ketergantungan pada } \\
\text { transaksi di bursa }\end{array}$ \\
\hline 3. Liquidation Value & Internal & Sekarang & $\begin{array}{l}\text { Ketergantungan pada kondisi } \\
\text { makro ekonomi }\end{array}$ \\
\hline 4. Sum of The Part & Eksternal \& & Proyeksi ke Depan & $\begin{array}{l}\text { Ketergantungan pada } \\
\text { perhitungan sinergi dan biaya }\end{array}$ \\
\hline 5. Discounted Cash Flow & $\begin{array}{l}\text { Eksternal \& } \\
\text { Internal }\end{array}$ & Proyeksi ke Depan & $\begin{array}{l}\text { Faktor suku bunga yang } \\
\text { dipergunakan }\end{array}$ \\
\hline 6. Relative Value & $\begin{array}{l}\text { Eksternal \& } \\
\text { Internal }\end{array}$ & Sekarang & $\begin{array}{l}\text { Perbandingan dengan } \\
\text { perusahaan sejenis }\end{array}$ \\
\hline
\end{tabular}

\section{REFERENSI}

Andriosopoulos, Dimitris, Yang, Shuai dan Li, Wei-an (2015) The market valuation of M\&A announcements in the United Kingdom. International Review of Financial Analysis. ISSN 1057-5219, http://dx.doi.org/10.1016/j.irfa.2015.05.022

Baye, Michael R., (2010), Managerial Economics and Business Strategy. 7th ed. McGrawHill, ISBN-13: 978-0-07-337596-0 (alk.paper) ISBN-10: 0-07-337596-9 (alk. paper).

Bertsatos Georgios, Sakellaris Plutarchos, Tsionas Mike G., (2017), Did the Financial Crisis affect the Market Valuation of Large Systemic U.S. Banks? Athens University of Economics and Business, Working Paper Series 09-2017.

Bisnis Indonesia, Pailita Batavia Air Segera Berakhir Hasilnya Miris http://kabar24.bisnis.com/read/20180225/16/742910/pailit-batavia-air-segera-berakhirhasilnya-miris

Declerck Francis, (2016) Mergers \& Acquisitions in the Food Business: How did the 2002 and 2008/2009 Economic Crises Impact Corporate Valuation? Int. J. Food System Dynamics 7 (3), 2016, 183-195 DOI: http://dx.doi.org/10.18461/ijfsd.v7i3.731

Indopremier

Research

didownload

dari

https://www.indopremier.com/ipotnews/newsDetail.php?jdl=Bank_of_Tokyo_Bakal_Akui sisi_20_1\%_Saham_Danamon\&news_id=323694\&group_news=RESEARCHNEWS\&tagi ng_subtype $=J A P A N \&$ name $=\&$ search $=y \_g e n e r a l \& q=j e p a n g, \% 20 \&$ halaman $=1$

Johan, Suwinto, (2017) Bahan Kuliah Merger, Akuisisi dan Restrukturisasi, Program Magister Manajemen, Universitas Tarumanagara.

Li., Z.M., Jiang, J.J., (2014) Problems and Strategies of Cross-border Mergers and Acquisitions for Chinese Enterprises, ABC Journal of Advanced Research, Volume 3, No 1 ISSN : 23042621(p); 2312-203X (e)

Liputan 6 didownload dari http://tekno.liputan6.com/read/3230895/dapat-dana-dari-googlevaluasi-go-jek-meroket-rp-533-triliun

Nazzer, Stephane (2017), 9 methods of startup valuation explained, AsiaTech didownload pada tanggal 20 Februari 2018 https://www.techinasia.com/talk/9-method-startup-valuation

Nazir, Nahila Nazir, Malhotra, Amarjeet Kaur, (2017) The Effect of Ownership Structure On Market Valuation of Firms In India: Evidence From BSE-100 Index Companies, Academy of Accounting and Financial Studies Journal Volume 21, Number 1, 2017. 
Pospisil, Jiri, (2015) Valuation Data in The Process of M \& A, Procedia Economics and Finance 25 (2015) $106-115,16^{\text {th }}$ Annual Conference on Finance and Accounting, ACFA Prague, 2015, 29 $9^{\text {th }}$ May 2015.

Ruslim, Herman, (2008) Merger, Akuisisi dan Restrukturisasi, Kompetensi Jurnal Manajemen \& Bisnis Vol. 3, No. 1, Juni 2008.

Tikhile, Kavita S., (2014), Understanding Mergers and Acquisitions Process and Valuation, International Journal For Administration In Management, Commerce, and Economics Issue 2 ISSN : 2347-9558.

Undang-Undang No 5 Tahun 1999 tentang Larangan Praktek Monopoli dan Persaingan Usaha Tidak Sehat.

Undang-Undang No. 37 Tahun 2004 tentang Penundaan Kewajiban Pembayaran Utang. 